\title{
Erratum to: Development of a Lentiviral Vector and an Efficient Infection Method for Gene Therapy for p22phoxdefective Chronic Granulomatous Disease
}

Young Mee Kim $\cdot$ Huh Jung Sik $\cdot$ Moonjae Cho $\cdot$ Kyung Sue Shin

Published online: 31 August 2012

(B) Springer-Verlag 2012

Erratum to: J Korean Soc Appl Biol Chem (2012) 55, 497-506

DOI 10.1007/s13765-012-2098-1

One of the authors' names was misprinted. The author list should be corrected as follows.

Corrected author list

Young Mee Kim $\cdot$ Jung Sik Huh $\cdot$ Moonjae Cho $\cdot$ Kyung Sue Shin

The online version of the original article can be found under doi:10.1007/s13765-012-2098-1 